\title{
The Legacy of Jonathan A. Ship
}

\author{
Elisa M. Ghezzi, DDS, PhD \\ University of Michigan School of Dentistry, Ann Arbor, Michigan \\ *Corresponding author e-mail: eghezzi@umich.edu
}

Spec Care Dentist 28(4): 123-124, 2008

\section{JONATHAN A. SHIP - A REMEMBRANCE}

The recent death of Jonathan Ship, DMD was a great loss for us all in that we lost a friend, colleague, and researcher.

Jonathan received a BA in

Anthropology from the University of Pennsylvania in 1980 and a DMD in 1984. He completed his General Practice Residency at Montefiore Medical Center and in 1989 was a Fellow in Oral Medicine and Clinical Dental Research at the National Institutes of Dental Research under the guidance of Dr. Bruce Baum. He then went on to become a faculty member at the University of Michigan in 1992. In 2000 he moved to New York University as Professor of Basic Science and Craniofacial Biology.

The focus of his research was to gain a better understanding of the influence of aging, systemic diseases, and medications on oral health and function. His research investigations began with a systematic approach to assessing oral conditions in healthy populations of different-aged adults. Evaluations of olfaction, gustation, periodontal and mucosal diseases, dental caries, salivary function, and oral motor function were conducted in several large populations of healthy adults across the entire age spectrum. In general, his findings suggested that age per se, in the absence of major medical problems and their treatments, had little influence on the incidence or prevalence of oral diseases. Specifically, his research findings demonstrated that specific systemic conditions, medications, radiotherapy, and chemotherapy had greater adverse affects on the health and function of the oral cavity than the simple chronological passing of time in healthy adults.

Many of his studies focused on salivary physiology because of the role saliva plays in the protection and preservation of oral and pharyngeal health. Oral and systemic conditions traditionally associated with salivary dysfunction were examined in several population-based studies, taking into consideration multiple sociodemographic and biological factors: menopause, dehydration, diabetes, hypothyroidism, Sjögren's syndrome, menopause, periodontal diseases, medications, and head and neck radiotherapy.

Diabetes has multiple deleterious influences on oral health, but evaluation in the elderly has been limited. He initiated a prospective and longitudinal investigation assessing the role of age, glycemic control, and other sociodemographic and oral factors on the prevalence and incidence of dental caries, periodontopathogens, periodontal disease progression, and salivary function. His findings to date demonstrate that older adults with poor glycemic control are more likely to develop caries, periodontal attachment loss, and salivary hypofunction compared to well-controlled diabetics or age-, gender-, and race-matched non-diabetic controls.

Another area of his research was in salivary function in aging adults. The loss of physiological reserve has been a well-accepted phenomenon in the aging of most organ systems of the body. While most clinicians and scientists have assumed that this process occurs in the oral cavity as well, it has never been proven in an objective fashion. Using saliva as his test oral system, he initiated a double-blind placebo-controlled crossover designed clinical investigation using healthy young and older adults to assess objective and subjective measures of salivary function after administration of a potent antisialogogue (glycopyrrolate). The results demonstrated that there were markedly greater drug-induced salivary impairment and salivary inhibition in older adults compared to younger adults.

Jon was the principal investigator on a grant from the NIH for $\$ 26.7$ million. This was the largest grant received by any school at NYU. Jon clearly was a talented researcher as can be seen from his multiple publications and the fact that he was honoured by IADR as a

Distinguished Scientist in Geriatric Oral Research which is only awarded to one person each year. However, Jon's greatest strength was his concern for others which made him an excellent teacher and mentor. The following is a memory written by one of his fellows.

(Introduction written by Ronald Ettinger.)

$$
667 \text { Tho is Dr. Jon Ship?" my }
$$

"He is a great man." I replied. "He is one of the greatest men I have ever known."

Jon lived to be remembered. He did not touch a life without leaving a lasting impression ... on his students, his patients, his colleagues, his friends, and his family.

I had the privilege of being a fourth year dental student at the University of Michigan (UM) School of Dentistry when I met Jon during my hospital dentistry rotation. Dr. Ship left a mark on every student that rotated through that clinic. He had such a passion, love, and gift of 
teaching that students could not help but be captivated by his engaging style.

It was during that weeklong rotation that my life forever changed. Dr. Ship asked me to consider applying for the general practice residency (GPR) program at UM. Unfortunately, for his recruiting efforts, I had grown up in Ann Arbor, gone to undergrad and dental school at UM, and was looking forward to spending my one year residency anywhere but in Ann Arbor. He found the carrot that would entice me back by introducing me to the geriatric dentistry fellowship program. Geriatric dentistry was a passing thought early in my dental school career that was lost since I did not encounter anyone who knew about it or actually practiced it. I made a deal with Jon that if he wrote a letter that got me accepted into a GPR program, then I would consider the geriatric dentistry fellowship. Needless to say, when my GPR ended I was heading back to Ann Arbor.

I had the privilege of working with Jon for four years from 1996-2000. It was during those four years that I had the opportunity to be mentored by one of the giants of geriatric dentistry. A mentor profoundly influences one's professional life and decisions for a lifetime. Dr. Jonathan A. Ship, DMD, is the quintessence of a mentor.

The characteristic that I most respected in Jon as my mentor was his integrity. Jon was honest, reliable, upright, and a man of his word. I can recall the one instance of utter disappointment when an administrative decision had been made contrary to what he had told me would occur. I distinctly remember adamantly confronting him, and his humble response of sincerity expressing that he was just as shocked as I. He would never have intentionally misled me.

As a mentor, Jon served the role of a big brother and father figure, a protector and guide. Working in large academic and research institutions can be overwhelming for junior faculty with many competing responsibilities, agendas, and politics. Jon recognized this and intentionally taught us (me as well as my fellow fellows) about the system and

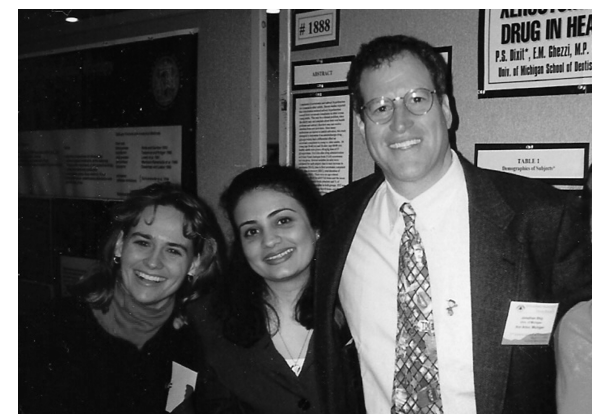

Elisa Ghezzi, DDS, PhD (left), Puravi Dixit Patel, DDS (center), Jonathan Ship, DMD (right).

how to navigate. He would guide me through discussions to determine career goals and create the path to achieve these goals. Jon was not afraid to ask the tough questions to help me figure out who I was and what I wanted . . . both professionally and personally.

Jon intentionally invested in others, and did not consider the repayment of his efforts. He taught me that investment in others is an academic institutional responsibility. "Elisa, you work to help each person reach their full potential, and if they leave and take their skills somewhere else, there is another mentor investing in someone else who will come to bring their skills to us." Jon had a way of planting words of wisdom that would stick with you. His advice was invaluable.

Jon understood the responsibility of mentorship ... one that he took very seriously and which lasts a lifetime and, in his case through his legacy, beyond. Even though it had been eight years since I directly worked with him, there was never a break in his mentorship. He was always accessible and available when I needed to seek his advice. I could always count on my 12:30 am e-mails to be answered by $4: 30$ am that morning. There was no question too trivial that he did not give his full attention. In the same vein, that privilege caused one to be conscientious and respectful of his time.

Jon could speak the honest truth in love, and could take the honest truth when dished out not so graciously. He would never be offended or poke fun even when it was well deserved. In one particular discussion to determine the best place for my husband to apply for his GPR, where I could transfer my NIH grant, we discussed living in New York City. I ranted for quite a while about why I would never work there given the commute, expense, etc. Jon politely listened never revealing that within the week he would accept his new position at NYU, and was very excited to move to that "abominable" city.

Jon knew appropriate boundaries. Although I would often be asked by others how Jon was doing, I never could answer the question. Jon did not share his personal life with us. He was our mentor, not our buddy. There was much freedom in this clearly defined role. In the early years when attending the Geriatric Oral Research Group receptions with him at the International Association of Dental Research meetings, he would introduce us to a few people and then leave us to navigate the waters on our own forcing us to develop our most treasured friendships with others in the international geriatric dentistry community.

Jon Ship loved his work, and that love spilled out into the lives of those working with him. Treating patients was an honor, research was exciting, and writing papers was an accomplishment. Dr. Ship could pull the best effort out of others, rope you into any project, and have you sitting back when the manuscript was done realizing how much you learned about yourself through the work. This past year Jon asked me to write a chapter with Judith Jones for the new edition of the Textbook of Geriatric Dentistry. Realizing it was the last request I would receive, I agreed. Thanks to Jon, I now know I hate writing book chapters.

A mentor leaves a lasting mark that defines one professionally. Although an epidemiologist by training, my true passion is clinical research, particularly intervention trials. When attempting to explain why I had inadvertently omitted a statement regarding a desire to practice epidemiology in my PhD application, I realized the answer. It was because Dr. Jonathan Ship is my mentor and he is a clinical researcher. That is why I am a geriatric dentist with an interest in clinical intervention trials... just not spit. 